\title{
Detection of polymorphism within leptin gene in Egyptian river buffalo and predict its effects on different molecular levels
}

\author{
Karima F. Mahrous ${ }^{1+}$, Mohamad M. Aboelenin ${ }^{1 *+}$ (D) Mohamed A. Rashed ${ }^{2}$, Mahmoud A. Sallam² and \\ Hossam E. Rushdi ${ }^{3}$
}

\begin{abstract}
Background: Leptin (LEP) regulates the glucose homeostasis directly and centrally by the regulation of the insulin levels or indirectly by alternation of the levels of the other glucose metabolism regulator hormones. The present investigation studied the polymorphism in LEP gene which is related to fertility in 81 female Egyptian river buffalo.

Results: The PCR-RFLP pattern of the gene using the restriction enzyme Eco91l showed that all the animals had monomorphic pattern in the studied gene which consists of CC. A 511-bp fragment from LEP gene was amplified and sequenced. The homology between the amplified LEP gene fragment in buffalo and cattle, sheep, goat, human, and mouse on the nucleotides sequence level was 99, 97, 97, 87, and 79\%, respectively, and on the translated amino acids sequence level was 100,98, 98, 85, and 82\%, respectively. Several SNPs were detected; among them, the T27C SNP disrupted an intronic splicing silencer. The A114G, A310G, G263A, and G379A SNPs disrupt exonic splicing enhancers, and the last two SNPs create new exonic splicing enhancers. The A114G, C163A, A211G, G288A, A310G, A322G, G330C, C348T, T360C, and G379A SNPs cause S71G, T87 N, N103S, E129K, E136G, Y140C, E143Q, R149W, S153P, and R159Q amino acids mutations. N103S, E129K, E136G, Y140C, E143Q, and S153P were classified as deleterious mutations. Y140, E143, N103, and R149 were the most conserved among the mutated amino acids. S71G only increased the stability of the leptin protein while the remaining mutations decreased it.
\end{abstract}

Conclusion: Four SNPs were revealed among the tested animals. Twenty-one SNPs were found between the sequenced amplicon and the buffalo records in the Genbank. Some SNPs were predicted to have several effects on different biological processes like mRNA splicing, protein stability, and the gene functions.

Keywords: Egyptian river buffaloes, Leptin, PCR-RFLP, SNP

\section{Background}

Leptin (LEP) is a hormone mainly synthesized in the white adipose tissue in addition to other tissues. The premature and inactive form of leptin protein consists of 167 amino acids, but their mature functional polypeptides consist of 146 amino acids [1]. Leptin has important role in the energy and glucose homeostasis and plasma glucose levels [2]. Vallinoto et al. [3] revealed that the river buffalo and cattle have the

\footnotetext{
* Correspondence: Mohamed2000mail@yahoo.com

${ }^{\dagger}$ Karima F. Mahrous and Mohamad M. Aboelenin contributed equally to this work.

${ }^{1}$ Cell Biology Department, National Research Centre, Giza, Egypt

Full list of author information is available at the end of the article
}

same basic structure of leptin gene which consists of 3 exons separated with 2 introns, the start and stop codons are located in exon 2 and exon 3, respectively, but exon 3 is untranslatable. The authors identified 1 microsatellite and 3 SNPs (single nucleotide polymorphism) in the buffalo leptin gene. They recognized the chromosomal location of the river buffalo leptin gene on BBU8q32.

Liefers et al. [4] used polymerase chain reactionrestriction fragment length polymorphism (PCR-RFLP) to genotype 323 Holstein-Friesian heifers based on A59V SNP mutation in leptin protein due to $\mathrm{C}$ to $\mathrm{T}$ SNP placed in the position 95 from the start of LEP- 
exon 3 which change an amino acid in position 59 of leptin protein from alanine to valine. They took blood samples from each animal starting from 30 days before to 80 days after parturition, and the leptin concentrations were analyzed in each sample. The authors found that the animals with TT genotype had high leptin concentration during the last 30 days of pregnancy compared to CC and CT genotypes. Yazdani et al. [5] investigated the effect of $\mathrm{A} 59 \mathrm{~V}$ variant in leptin protein in 255 Iranian Holstein cows using RFLP-HphI, and they indicated that the AA genotype had pregnancy length that is significantly longer than $A B$ and $B B$ genotypes, and also, Clempson et al. [6] studied A59V replacement within leptin protein in 509 Holstein Friesian heifers and showed that the heifers with CC genotype were younger at the first service and first calving ages. Komisarek and Antkowiak [7] screened 219 Jersey cows using PCRRFLP method by restriction enzyme Eco91I (RFLPEco91I) to identify the relationship between fertility and A59V SNP. TT genotype had shorter time of days open and calving interval in addition to lower number of inseminations per conception than CC and CT genotypes.

Orrú et al. [8] discovered 1 SNP in exon 2, 5 SNPs in exon 3, and 8 intronic SNPs by analysis; the sequence of 2 fragments represents exons 2 and 3 and part of intron 1 that covers all the leptin gene coding sequence in 32 Italian River Buffalo and 2 Egyptian river buffalo, while Seong and Kong [9] investigated the sequence of leptin gene-exon 3 in 20 American Murrah Buffalo and 350 Bulgarian Murrah Buffalo and found 3 SNPs between these populations.

Kale et al. [10] discovered 2 SNPs within the exon 3 of leptin gene in 65 Murrah, 10 Surti, and 10 Bhadawari breeds of buffaloes using the single-stranded conformation polymorphism (SSCP) technique and the sequencing of the amplified region. However, Datta et al. [11] analyzed and studied the sequence of intron 1, exons 2, intron 2, and exons 3 within leptin gene among Murrah buffaloes and indicated variations in 8 positions compared to cattle. Di Gregorio et al. [12] explored the sequence of a region within leptin gene covers a part of intron 1, full exon 2, and part of Exon 3 and represents the complete coding sequence for the 167 amino acids of the premature leptin in the water buffalo, goat, cattle, and sheep. They indicated that the sequence of the leptin gene in goat and sheep is more homologous than water buffalo and cattle.

The present study aimed to investigate the genetic polymorphisms in leptin gene (LEP) within Egyptian buffalo females which could be used as molecular markers in marker-assisted selection (MAS)-based breeding programs to improve the fertility of Egyptian buffalo females.

\section{Methods}

This investigation was carried out in the Cell Biology Department, National Research Centre, Giza, Egypt.

\section{Sample collection and DNA extraction}

A total of 81 blood samples were collected from healthy and unrelated Egyptian river buffalo females. Thirty blood samples were collected from the farm of Cattle Information System/Egypt (CISE), and 51 blood samples were collected from the Agricultural Experiments Station (AES), Faculty of Agriculture, Giza, Egypt. Ten milliliters of blood samples were collected in sterile 15 $\mathrm{ml}$ tubes containing $0.5 \mathrm{ml}$ of $0.5 \mathrm{M}$ EDTA solution $(\mathrm{pH}$ 8.0). Genomic DNA was extracted from the whole blood samples according to the method described by Miller et al. [13] with minor modifications. The DNA concentration was determined using Nano Drop1000 thermo scientific spectrophotometer and then diluted to the working final concentration of $50 \mathrm{ng} / \mu \mathrm{l}$.

\section{Animal genotyping and leptin amplicon sequencing}

A DNA fragment which is a part of LEP gene was amplified using forward (5'TGCCCTCTCTCCCACTGA3') and reverse (5'CTGGTGAGGATCTGTTGGTAGGTC $\left.3^{\prime}\right)$ primer pair which were designed using Primer3 online software (http://primer3.ut.ee/; [14]) based on the sequence of GenBank record HE605297.1. Polymerase chain reaction (PCR) was performed in $25 \mu$ of reaction volume, which included $50 \mathrm{ng}$ of genomic DNA, $50 \mathrm{ng}$ of each primer, $200 \mu \mathrm{M}$ of each dNTP, $2.5 \mu \mathrm{l}$ of $10 \times$ PCR buffer, and $0.5 \mathrm{U}$ of Taq DNA polymerase (Promega, Madison, WI, USA). Amplification was carried out in a thermocycler which was programmed as follows: an initial start separation cycle at $94^{\circ} \mathrm{C}$ for $2 \mathrm{~min}, 35$ cycles including a denaturation step at $94{ }^{\circ} \mathrm{C}$ for $30 \mathrm{~s}$, an annealing step at $60^{\circ} \mathrm{C}$ for $30 \mathrm{~s}$, a polymerization step at $72{ }^{\circ} \mathrm{C}$ for $45 \mathrm{~s}$, and a final extension cycle at $72{ }^{\circ} \mathrm{C}$ for $10 \mathrm{~min}$. The PCR products were screened by electrophoresis on a $2 \%$ agarose gel in $0.5 \times$ of TBE buffer which was stained with ethidium bromide and visualized with an UV transilluminator. PCR product was digested by Eco91I restriction enzyme (Thermo Scientific, Dreieich, Germany) at $37^{\circ} \mathrm{C}$ for $30 \mathrm{~min}$ according to the procedure provided by the manufacturer. Digested products were separated by electrophoresis on a $2 \%$ agarose gel in $0.5 \times$ of TBE buffer which was stained with ethidium bromide and visualized with an UV transilluminator $[15,16]$.

\section{Purification and sequencing of PCR products}

A longer segment from leptin gene was amplified using the same forward primer (5'TGCCCTCTCTCCCACTGA3') in addition to new reverse primer ( $5^{\prime}$ CCGCTGGCCTGCATA AAG $3^{\prime}$ ) primer pair. The PCR products of selected samples were purified using GeneJET Gel Elution Kit (Thermo 
Scientific, Dreieich, Germany). The purified PCR products were sequenced using an automated sequencing service (Macrogen, Korea).

\section{Data analysis}

Alignment of the sequences was performed with the GenBank database BLAST tool (https://blast.ncbi.nlm. nih.gov/Blast.cgi) to identify the homology between the amplified LEP fragment and the orthologues sequences on the GeneBank database. The splicing site strength was predicted using SplicePort [17], and the effects of discovered SNPs and RNA cis-regulatory elements were investigated using RegRNA 2.0 [18] online software. To predict the effects of the non-synonymous SNPs on protein functions, the consensus classifier software PredictSNP was used which combined the results of MAPP, PhD-SNP, PolyPhen-1, PolyPhen-2, SIFT, and SNAP software [19]. The 3D tertiary structure of the proteins was predicted using the I-TASSER server [20], and the effect of the detected mutation on the protein stability was calculated by the INPS3D server [21]. The conservation score of the amino acids within the target proteins was computed using the ConSurf server [22].

\section{Results}

A fragment from the buffalo LEP gene (166 bp) was amplified by PCR using a mutated forward primer (Fig. 1a, c), and the amplicons were digested by Eco91I. PCR-RFLP pattern showed that all the buffalos had a single undigested band with molecular weight of $166 \mathrm{bp}$ which refers to CC genotype (Fig. 1b). PCR-RFLP results were confirmed by direct sequencing of $511 \mathrm{bp}$ amplified fragment within LEP gene (using the same reverse primer and a new forward primer). The sequencing results (Fig. 1c) show that the $C$ allele (which codes for the amino acid Ala) was found in the target site. Allele $\mathrm{C}$ mutates the Eco91I enzyme restriction site (GGTNACC, allele T) to an unrestrictable site (GGE्NACC, allele C).

Sequencing of the amplified sequence from LEP gene Sequencing of the amplified region of the Egyptian buffalo LEP gene (GenBank accession numbers MF490262-

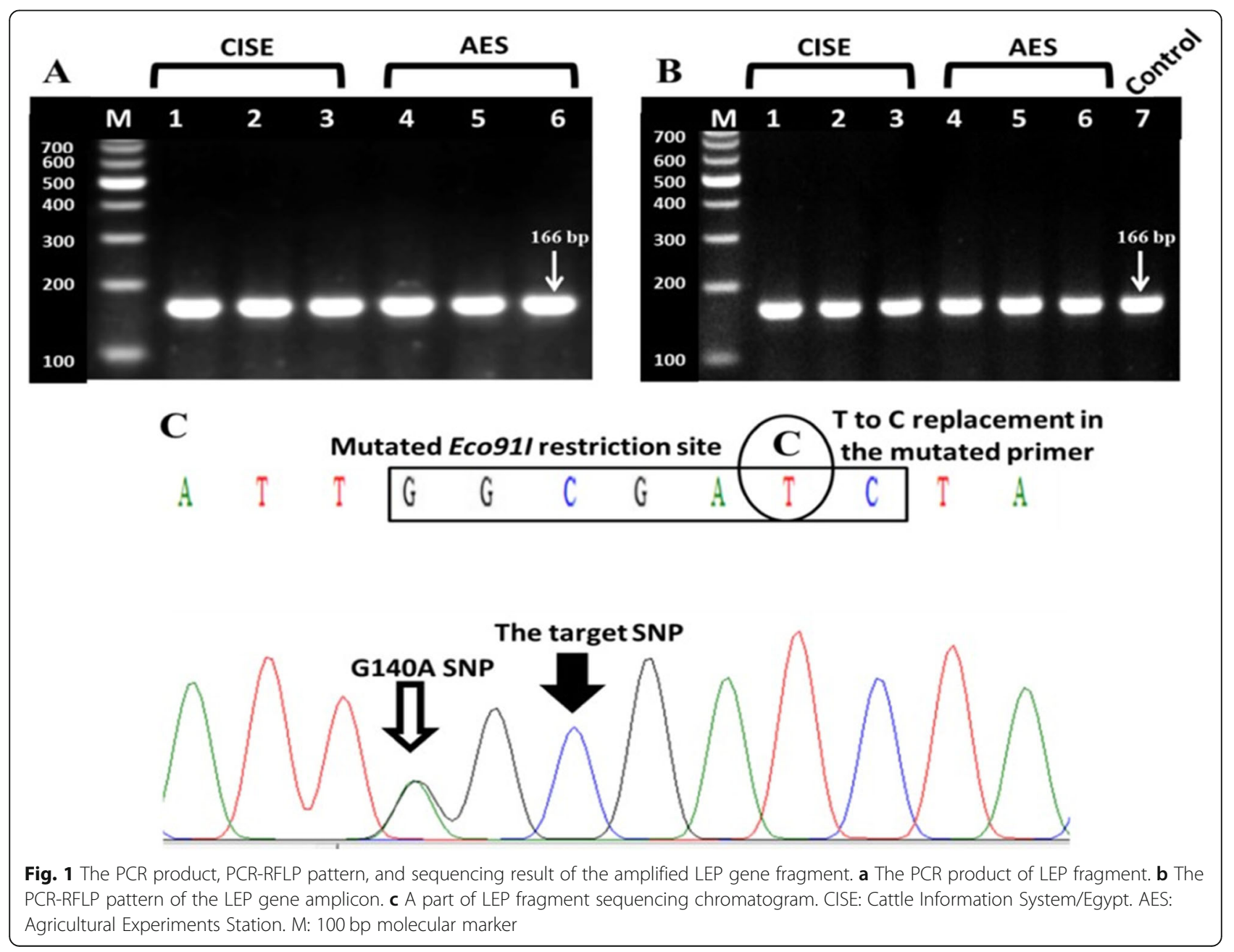


MF490277) produced a nucleotide sequence of $511 \mathrm{bp}$ which covers a part of intron 2 (1-47 bp), coding region of exon 3 (48-404 bp), stop codon (405-407 bp), and 3' UTR (408-511 bp; Fig. 2a).

Within the Egyptian buffalo samples, 4 transition SNPs (C32T, G140A, G263A, and G379A) were revealed in Fig. 2. The alleles of the last 3 SNPs in addition to 2 transversion SNPs and 19 transition SNPs were found between sequenced amplicon and the other buffalo breed records in GenBank; 22 of these SNPs were exonic and 2 were intronic (Table 1).
Comparison of the amplified region in LEP gene among some species

The sequence of amplified LEP gene fragments and the translated amino acid sequence of the coding region within this fragment were aligned with the orthologous genes in human, mouse, sheep, cattle, and goat (Fig. 3).

\section{Predicting the effect of the detected SNPs within LEP} gene on the splicing sites strength cis-acting splicing regulatory elements

SplicePort software was used to detect the strength of both known splicing sites ( $3^{\prime}$ splicing site of intron 2, 5' splicing

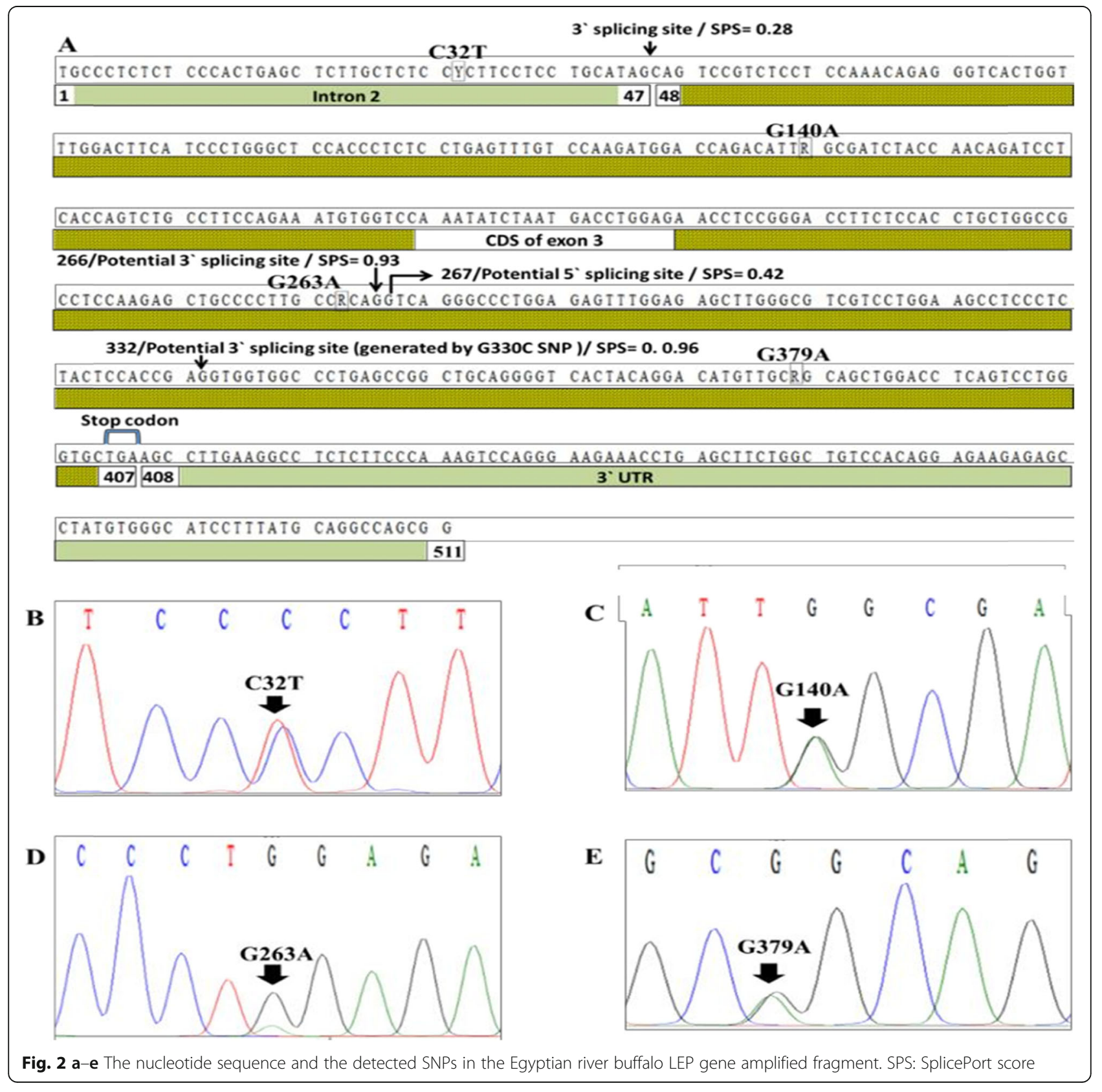


Table 1 Detected SNPs in the amplified LEP sequence and its homologs Bubalus bubalis sequences in the GenBank database and previous studies

\begin{tabular}{|c|c|c|c|}
\hline Region & SNP & Alleles & GenBank accession number or reference \\
\hline Intron 2 & T27C & $C$ & KP897166.1, EU825672.1, GQ385228.1 \\
\hline Intron 2 & C32T & $C$ & $\begin{array}{l}\text { HE605297.1, AH013754.2, AF387814.1, EU888289.1, JN689387.1, AY338973.2, KP897165.1, } \\
\text { KP897166.1, DQ831143.1, DQ831142.1, EU825674.1, EU825673.1, EU825672.1, GQ385228.1, } \\
\text { DQ490986.1 }\end{array}$ \\
\hline Intron 2 & C33Т & T & GQ385228.1 \\
\hline Exon 3 & $\mathrm{~A} 114 \mathrm{G}$ & G & EU888289.1 \\
\hline \multirow[t]{3}{*}{ Exon 3} & G140A & $\mathrm{G}$ and $\mathrm{A}$ & {$[8]$} \\
\hline & & G & $\begin{array}{l}\text { HE605297.1, AH013754.2, AF387814.1, EU194869.1, EU199796.1, EU888289.1, KP864439.1, } \\
\text { NM_001290901.1, KP864440.1, KP864438.1, KP864436.1, KP864437.1, AY427959.1, } \\
\text { JN689387.1,DQ676889.1, AY338973.2, AY177609.1, JQ045625.1, KP897165.1, KP897166.1, } \\
\text { DQ831143.1, DQ831142.1, EU825674.1, EU825673.1, EU825672.1, GQ385228.1, DQ490986.1 }\end{array}$ \\
\hline & & A & DQ676890.1 \\
\hline Exon 3 & C163A & A & EU825672.1, EU825673.1, EU825674.1, GQ385228.1 \\
\hline Exon 3 & T197C & C & AY177609.1, JQ045625.1 \\
\hline Exon 3 & G206A & A & AY177609.1 \\
\hline Exon 3 & $\mathrm{~A} 211 \mathrm{G}$ & G & JQ045625.1 \\
\hline Exon 3 & C242T & $\mathrm{T}$ & EU078405.1 \\
\hline \multirow[t]{3}{*}{ Exon 3} & G263A & G and $A$ & {$[8,9]$} \\
\hline & & G & $\begin{array}{l}\text { HE605297.1, AF387814.1, EU194869.1, EU199796.1, KP864439.1, NM_001290901.1, } \\
\text { KP864438.1, AY427959.1, JN689387.1, DQ676890.1, DQ676889.1, AY177609.1, } \\
\text { JQ045625.1, KP897165.1, KP897166.1 }\end{array}$ \\
\hline & & A & AH013754.2, EU888289.1, KP864436.1, KP864437.1, KP864440.1, AY338973.2 \\
\hline \multirow[t]{2}{*}{ Exon 3} & G278A & G and $A$ & AF387814.1 \\
\hline & & A & KP864438.1, AY427959.1 \\
\hline Exon 3 & G278A & G and $A$ & {$[8]$} \\
\hline Exon 3 & T284C & C & AY177609.1, JQ045625.1 \\
\hline Exon 3 & G288A & A & AY177609.1 \\
\hline Exon 3 & С $302 \mathrm{~T}$ & T & AY177609.1, JQ045625.1 \\
\hline Exon 3 & A310G & G & KP864436.1, KP864437.1, KP864438.1. KP864439.1, KP864440.1 \\
\hline Exon 3 & C314T & T & AY177609.1, JQ045625.1 \\
\hline Exon 3 & A322G & G & JN689387.1 \\
\hline Exon 3 & G330C & C & JQ045625.1 \\
\hline Exon 3 & С $348 \mathrm{~T}$ & T & JQ045625.1 \\
\hline Exon 3 & T360C & C & HE605297.1 \\
\hline \multirow[t]{3}{*}{ Exon 3} & G379A & G and $A$ & {$[8,9]$} \\
\hline & & G & $\begin{array}{l}\text { HE605297.1, AH013754.2, AF387814.1, EU199796.1, KP864439.1, NM_001290901.1, } \\
\text { KP864440.1, KP864438.1, KP864436.1, KP864437.1, AY427959.1, DQ676889.1 }\end{array}$ \\
\hline & & A & EU194869.1, DQ676890.1 \\
\hline Exon 3 & G386A & A & KP864437.1 \\
\hline Exon 3 & T398C & $C$ & NM_001290901.1, AY427959.1 \\
\hline
\end{tabular}

site of intron 3) and potential splicing sites within the amplified LEP gene fragment and the effect of the detected SNPs on them (Fig. 2a). Furthermore, using RegRNA 2.0 software, six SNPs (T27C, C32T, A114G, G263A, A310G, and G379A) were found to have several potential effects on RNA cis-regulatory elements (Table 2).
Effect of the detected non-synonymous SNPs in LEP gene A114G, C163A, A211G, G288A, A310G, A322G, G330C, C348T, T360C, and G379A SNPs were found to be non-synonymous which caused S71G, T87N, N103S, E129K, E136G, Y140C, E143Q, R149W, S153P, and R159Q mutations in LEP polypeptide, respectively 


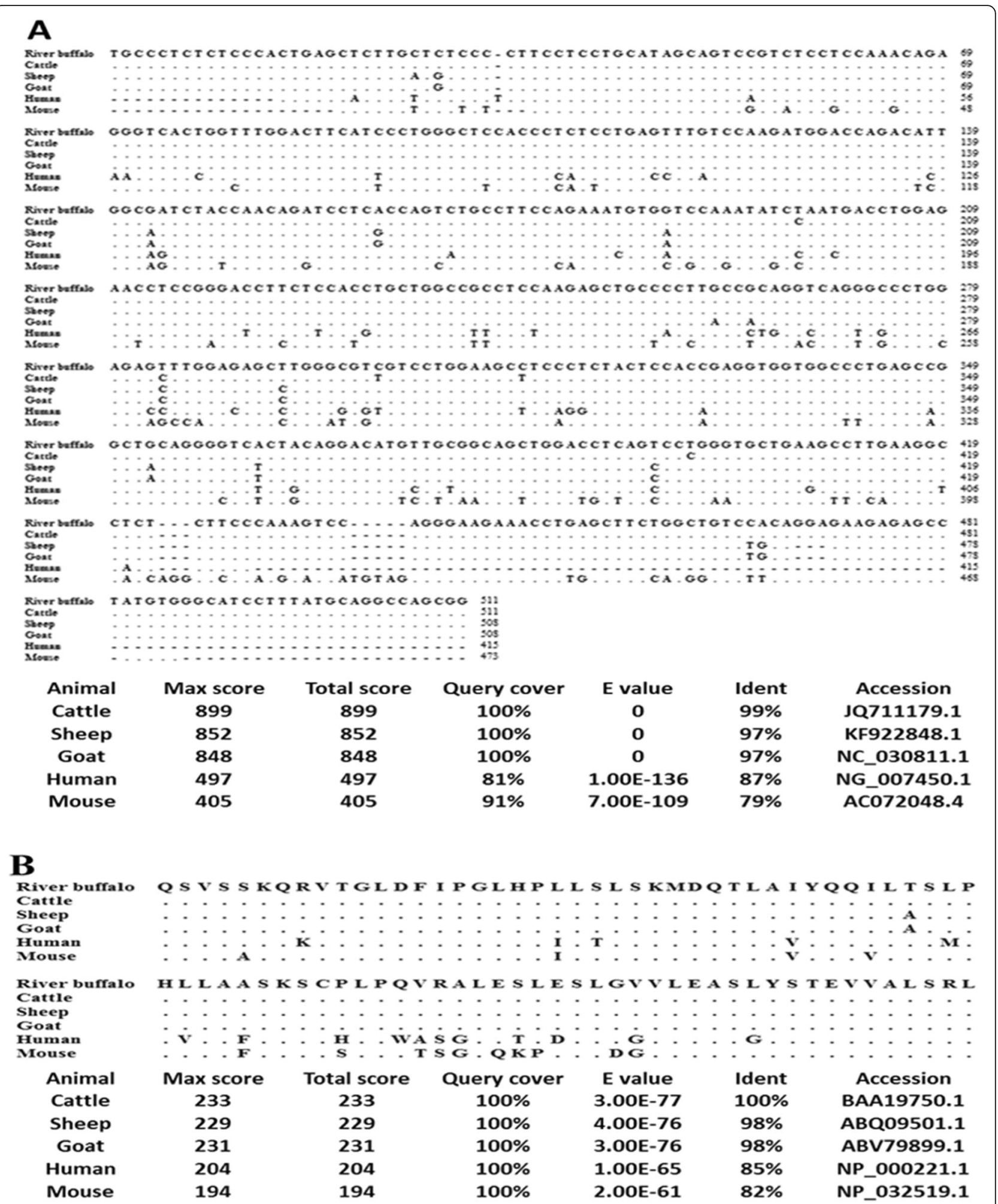

Fig. $\mathbf{3}$ The nucleotides and translated amino acid sequences homology between the amplified region of LEP gene in Egyptian river buffalo and some species. Multiple sequence alignment of the nucleotides (a) and translated amino acids (b) sequences 
Table 2 The effect of detected SNP within buffalo LEP gene on the RNA cis-acting splicing regulatory elements in LEP hrRNA

\begin{tabular}{|c|c|c|c|}
\hline SNP & Effect & Motif & Binding factor \\
\hline $\mathrm{T} 27 \mathrm{C}$ & Disrupts: intron silencer of c-src, exon n1 - Mus musculus & 26 c $\mathbf{T}$ ctc 30 & $\mathrm{PTB} / \mathrm{nPTB}, \mathrm{KSRP}, \mathrm{FBP}, \mathrm{hnRNP} \mathrm{H}, \mathrm{hnRNP} \mathrm{F}$ \\
\hline С $32 \mathrm{~T}$ & Creates: intron silencer of caspase-2, exon 9 - Mus musculus & $32 \underline{\mathbf{I}} \mathrm{cttcc} 37$ & PTB \\
\hline $\mathrm{A} 114 \mathrm{G}$ & Disrupts: exon enhancer of brca1, exon18 - Homo sapiens & 111 ctgㅁgtt 117 & SFRS1 (SF2/ASF) \\
\hline \multirow[t]{3}{*}{ G263A } & Disrupts: asf/sf2 - exonic splicing enhancer & 262 cG caggt 268 & ASF/SF2 \\
\hline & Creates: SRp40-exonic splicing enhancer - Homo sapiens & $263 \underline{\text { Acagg }} 267$ & SRp40 \\
\hline & Creates: SRp55 - exonic splicing enhancer - Homo sapiens & 261 ccㅡㅗagg 267 & SRp55 \\
\hline A310G & Disrupts: GH exon 5 exon splicing enhancer - Bostaurus & 308 gg소ag 312 & ASF/SF2 \\
\hline \multirow[t]{2}{*}{ G379A } & Disrupts: SRp55-exonic splicing enhancer - Homo sapiens & $376 \operatorname{tgc} \underline{\mathbf{G g} c} 381$ & SRp55 \\
\hline & Creates: SRp40-exonic splicing enhancer - Homo sapiens & $376 \operatorname{tgc} \mathbf{A g c} 381$ & SRp40 \\
\hline
\end{tabular}

(based on the CDS of LEP gene in the GenBank record NW_005782251.1). The non-synonymous SNPs in LEP gene were evaluated by PredictSNP which combined the results of six programs which utilize different methods to predict the deleterious effect of the non-synonymous SNP (Fig. 4). The amino acid conservation analysis on 180 leptin amino acid sequences from many species was performed using ConSurf server (Fig. 5), and the amino acids were classified based on conservation score ranging from 1 (variable) to 9 (conserved).

The 3D tertiary structure of river buffalo mature leptin peptide (146 amino acids) was predicted using the ITASSER server, and the effect of the discovered nonsynonymous on the stability of tertiary structure of mature leptin peptide was predicted using the INPS3D server based on free energy difference $(\Delta \Delta \mathrm{G}=$ the free energy change from wild type to mutant) which was calculated (Fig. 6).

\section{Discussion}

The present investigation studied the polymorphism in LEP gene which related to fertility in 81 female Egyptian river buffaloes. PCR-RFLP pattern using Eco91I of the target fragment showed that all the investigated buffaloes had CC genotype which was confirmed by direct sequencing. In agreement with the current results, some investigators confirmed the $\mathrm{CC}$ genotype as the only detected genotype among several river buffalo breeds [3, 8-12]. But in cattle, the frequencies of CT and TT genotypes were $34 \%$ and $8 \%$ (Liefers et al. [4]), $47.03 \%$ and 9.13\% [7], 38.8\% and 2.4\% [5], and 33\% and 6\% [6], respectively. Some studies found that the SNPs which are related to some reproduction traits in cattle were monomorphic in Egyptian buffaloes [23, 24].

Interestingly, both Eco91I [7] and HphI [4] enzymes which are used for C to T SNP (A59V mutation) detection in cattle are not suitable in any future studies on Egyptian buffalo to detect this A59V mutation because a G140A SNP was discovered by sequencing of LEP amplicon (Fig. 1c), and the A allele of the discovered
SNP disrupts Eco91I and HphI restriction sites. This finding means that Eco91I and HphI will not be able to differentiate the 2 alleles of $\mathrm{A} 59 \mathrm{~V}$ mutation. It could be suggested that the 2 alleles of LEP gene $C$ to TSNP (A59V) could be differentiated in any future studies on river buffalo using a PCR reaction which could be carried out by the same forward primer designed in this study in combination with the mutated primers (5' CTGGTGAGGATCTGTTGGTCGATC $\left.3^{\prime}\right)$ or $\left(5^{\prime}\right.$ CTGGTGAGGATCTGTTGGT $\underline{T}$ GATC 3') which will produce an amplicon that has the restriction site of $P v u I$ (CGATCG which will cut C allele) or BclI (TGATCA which will cut $\mathrm{T}$ allele), respectively.

Four SNPs (C32T, G140A, G263A, and G379A) were detected within the Egyptian buffalo samples. The alleles of G140A, G263A, and G379A SNPs in addition to 21 SNPs were found between in the leptin gene in the sequenced fragment of the Egyptian buffalo and the other buffalo breed records for the same gene in GenBank. The $\mathrm{T}$ allele of C32T intronic SNP was unique and was detected in Egyptian buffalo within this investigation only and was not detected in any buffalo records in GenBank or previous studies on river buffalo [3, 8-12].

The Brazilian buffalos in the study of Vallinoto et al. [3] had both alleles of G263A and G278A SNPs but had the G allele only of G140A and G379A SNPs compared to Egyptian buffaloes, and the Brazilian and Egyptian breeds are monomorphic for G386A SNP. Both of the Italian [8] and Egyptian buffaloes were polymorphic for G140A and G379A SNPs, but in contrast to Egyptian buffaloes, the Italian buffaloes were monomorphic for G263A SNP and polymorphic for G278A SNP. The Philippine buffaloes [9] had the two alleles of G263A and G379A SNPs exactly like the Egyptian breeds.

Compared to the Egyptian buffaloes, the Indian buffaloes [10] were polymorphic for G379A SNP and also were monomorphic for G140A and G263A SNPS (had $\mathrm{G}$ alleles of both SNPs), and the Egyptian buffaloes had the $\mathrm{C}$ allele of C242T SNP while the Indian buffaloes had $\mathrm{T}$ allele. In the studied sample of Italian buffaloes 


\begin{tabular}{|c|c|c|c|c|c|c|c|c|c|}
\hline & & & & neutral & deletts & $X X \% \theta$ & ted accuracy & & \\
\hline SNP & $\begin{array}{l}\text { Affected } \\
\text { codons }\end{array}$ & Mutation & PredictSNP & MAPP & PhD-SNP & PolyPhen-1 & PolyPhen-2 & SIFT & SNAP \\
\hline A114G & AGT-GGT & S71G & $65 \%$ & $57 \%$ & $78 \%$ & $67 \%$ & $71 \%$ & $43 \%$ & $61 \%$ \\
\hline C163A & $A C C-A A C$ & T87N & $63 \%$ & $66 \%$ & $58 \%$ & $67 \%$ & $79 \%$ & $45 \%$ & $55 \%$ \\
\hline A211G & AAC-AGC & $\mathrm{N} 103 \mathrm{~S}$ & $87 \%$ & $76 \%$ & $68 \%$ & $59 \%$ & $65 \%$ & $53 \%$ & $56 \%$ \\
\hline G288A & GAG-AAG & E129K & $83 \%$ & $72 \%$ & $72 \%$ & $67 \%$ & $75 \%$ & $77 \%$ & $71 \%$ \\
\hline A310G & GAA-GGA & E136G & $65 \%$ & $78 \%$ & $72 \%$ & $59 \%$ & $40 \%$ & $79 \%$ & $62 \%$ \\
\hline A322G & TAC-TGC & $\mathrm{Y} 140 \mathrm{C}$ & $87 \%$ & $82 \%$ & $68 \%$ & $74 \%$ & $81 \%$ & $79 \%$ & $89 \%$ \\
\hline G33OC & GAG-CAG & E143Q & $87 \%$ & $76 \%$ & $58 \%$ & $74 \%$ & $81 \%$ & $53 \%$ & $89 \%$ \\
\hline С348T & CGG-TGG & $\mathrm{R} 149 \mathrm{~W}$ & $87 \%$ & $59 \%$ & $61 \%$ & $74 \%$ & $81 \%$ & $53 \%$ & $89 \%$ \\
\hline T360C & TCA-CCA & S153P & $55 \%$ & $63 \%$ & $72 \%$ & $74 \%$ & $45 \%$ & $71 \%$ & $81 \%$ \\
\hline G379A & CGG-CAG & $\mathrm{R} 159 \mathrm{Q}$ & $83 \%$ & $76 \%$ & $98 \%$ & $67 \%$ & $87 \%$ & $87 \%$ & $71 \%$ \\
\hline
\end{tabular}

[12], the animals had G alleles of G140A, G263A, and G379A SNPs in addition to C allele of T360C SNP in opposition to Egyptian buffaloes.

Blasting of the nucleotide sequence of Egyptian river buffalo LEP gene amplified region against GenBank database displayed that cattle had the highest homology score (99\%) compared to sheep (97\%), goat (97\%), human (87\%), and mouse (79\%). On the other hand, the homology of the translated amino acid sequence from full coding region of Egyptian river buffalo LEP geneexon 3 and the similar sequence in cattle, sheep, goat, human, and mouse was $100 \%, 98 \%, 98 \%, 85 \%$, and $82 \%$, respectively. The homology of the translated amino acid sequence was higher in the target organisms than their DNA sequences homology.

Using the SplicePort software, the score of the 3' splicing site in the end of intron 2 (in the position 47) was calculated to be 0.28 which was lower than the score of the intron 2-3' splicing site in human (0.31) which could be replaced by another 3 ' splicing site located 3 bp downstream it that lead to protein isoform which lacks glutamine at position 49 of the mature peptide [25]. This weak splicing site could be affected by flanked cis-acting splicing regulatory elements [26]. The SplicePort software detects potential $3^{\prime}$ splicing sites with a higher score than the regular $3^{\prime}$ splicing site located in the positions $266(0.93)$ and $469(0.87)$ in addition to $5^{\prime}$ splicing site (0.42) in the positions 267. G330C SNP generated a $3^{\prime}$ splicing site in position 332 with a score equals 0.96 . These sites may act as cryptic splicing sites which could be activated by some mutations or naturally without any mutations leading to change in the final transcription products [27-31].

Moreover, six SNPs were predicted to have different effects on RNA cis-regulatory elements. Table 2 shows that T27C and C32T SNPs are very close to the 3' 


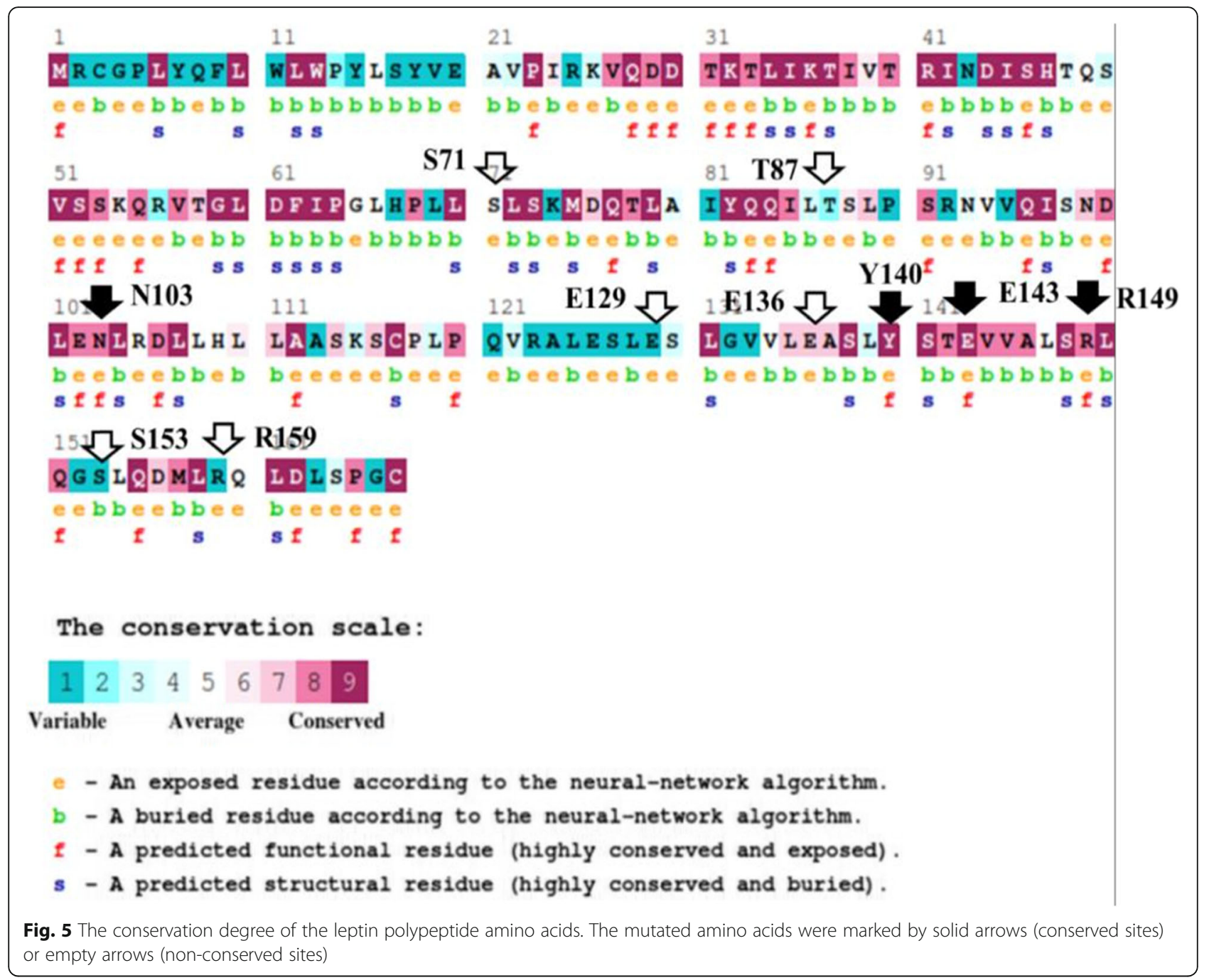

splicing site of intron 2 and the first SNP disrupts an intron splicing silencer while the lastone creates a new intron splicing silencer. In the exon 3, both A114G and A310G SNPs disrupt two exonic splicing enhancers, but G263A and G379A SNPs disrupt two exonic splicing enhancers and in the same time the two SNPs create new exonic splicing enhancers. Disruption, creation, or changing the number of the cis-acting splicing regulatory elements could change the splicing efficiency and affect the different consequence processes like alternative splicing and intron retention which affect the final protein sequence and structure $[32,33]$.

Ten non-synonymous were found among the detected SNPs, and their potential effects on LEP protein functions were predicted (Fig. 4). The results showed that all the programs classified E129K and R159Q mutations as neutral mutations with a total PredictSNP expected accuracy of 83\%. S71G and T87N mutation were classified as neutral mutations by PHD-SNP, POLYPHEN-1, POLYPHEN-2, and
SNAP and as deleterious mutations by MAPP and SIFT, so the PredictSNP software classified them as neutral mutations but with 65 and $63 \%$ accuracy only. Furthermore, N103S, Y140C, E143Q, and R149W were evaluated by the six software as deleterious mutations with $87 \%$ combined accuracy by PredictSNP. E136G and S153P mutations were predicted as deleterious mutation by all the programs except PHDSNP in the case of E136G and PHD-SNP and SIFT in the case of S153 with a 65 and 55\% PredictSNP accuracy, respectively.

The amino acid conservation analysis showed that the amino acids S71, T87, E129, E136, S153, and R159 are not conserved in LEP polypeptide. The amino acids Y140 and E143 had the highest conservation score followed by the amino acids N103 and R149. These findings confirm that the conserved amino acids had an important functional or structural role on the native LEP protein [22], so the mutation in these amino acids could have a damaging effect on LEP protein. 


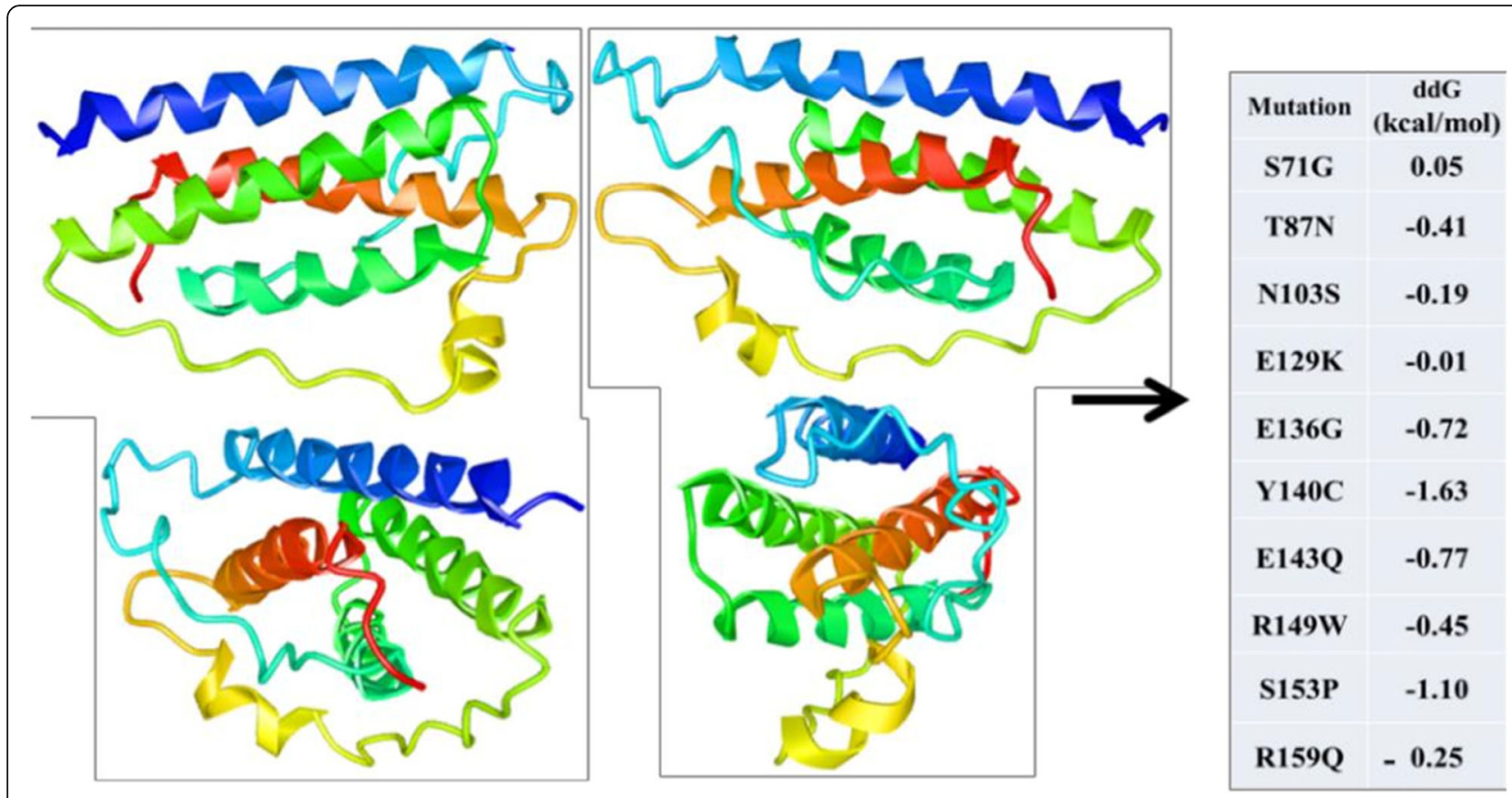

Fig. 6 The predicted 3D tertiary structure of the mature river buffalo leptin peptide from several views and the effect of the detected mutations on its stability

Finally, the effect of revealed non-synonymous on the stability of 3D tertiary structure of river buffalo mature leptin peptide was predicted (Fig. 6). S71G only increased the stability of the leptin protein by $0.05 \mathrm{kcal} /$ mol. T87N, N103S, E129K, E136G, Y140C, E143Q, R149W, S153P, and R159Q lowered the stability of mature leptin peptide tertiary structure by $-0.41,-0.19$, $0.01,-0.72,-1.63,-0.77,-0.45,-1.10$, and -0.25 $\mathrm{kcal} / \mathrm{mol}$, respectively. Y140C and S153P mutations reduced the stability of mature leptin peptide tertiary structure by more than $-1 \mathrm{kcal} / \mathrm{mol}$ which added more evidence supporting the damaging effect of these mutations [34]. Finally, the amino acid N103 in the leptin polypeptide is conserved in human and river buffalo, and the $\mathrm{N}$ to $\mathrm{K}$ mutation which occurs in this amino acid has a damaging effect on the physiological function of human LEP protein [35].

\section{Conclusions}

In this study, the polymorphism in LEP gene in 81 female Egyptian river buffalo was investigated by PCR-RFLP Eco91I, and all the animals had the CC monomorphic pattern. Four SNPs were revealed among the tested animals by sequencing a 511-bp fragment from LEP gene. Moreover, 21 SNPs were found between the sequenced amplicon and the homologous buffalo records in Genbank. The homology between the amplified LEP gene fragment in buffalo and cattle, sheep, goat, human, and mouse on the nucleotides sequence level was 99, 97, 97,
87 , and $79 \%$, respectively, and on the translated amino acids sequence level was $100,98,98,85$, and $82 \%$, respectively. The T27C SNP disrupts an intronic splicing silencer. The A114G, A310G, G263A, and G379A SNPs disrupt exonic splicing enhancers, and the last 2 SNPs create new exonic splicing enhancers. The A114G, C163A, A211G, G288A, A310G, A322G, G330C, C348T, T360C, and G379A SNPs cause S71G, T87N, N103S, E129K, E136G, Y140C, E143Q, R149W, S153P, and R159Q amino acid mutations. N103S, E129K, E136G, Y140C, E143Q, and S153P were classified as deleterious mutations. Y140, E143, N103, and R149 were the most conserved among the mutated amino acids. S71G only increased the stability of the leptin protein while the remaining mutations decreased it.

\section{Abbreviations \\ LEP: Leptin; MAS: Marker-assisted selection; PCR: Polymerase chain reaction; RFLP: Restriction fragment length polymorphism; SNP: Single nucleotide polymorphism; SPS: SplicePort score; SSCP: Single-stranded conformation polymorphism}

\section{Acknowledgements}

Not applicable.

\section{Authors' contributions}

KFM, MMA, and MAR designed the work and analyzed the data. KFM, MMA, MAR, and MAS wrote the manuscript. MMA performed the practical work of all the experiments. HER collected the blood samples. All authors read and approved the final manuscript. 


\section{Funding}

The financial support of the National Research Centre to cover all the materials which used in this work is greatly acknowledged which was provided as a "Thesis Support Funding."

\section{Availability of data and materials}

All data generated or analyzed during this study are included in this published article.

\section{Ethics approval and consent to participate}

Blood samples were collected from buffaloes under veterinary supervision and comply with local and international guidelines, international recommendations for the care and use of animals (Federation of Animal Science Societies, 2010). Blood samples were collected from the farms of Cattle Information System/Egypt (CISE) and Agricultural Experiments Station (AES) which are belong to Faculty of Agriculture, Cairo University, Giza, Egypt after a written approval from Faculty of Agriculture. The protocol and methodologies were approved with the National Research Centre (NRC) authorized committee, NRC, Giza, Egypt in its meeting in April 16, 2014 under title "PhD proposal of Mohamad Aboelenin, Cell biology department".

\section{Consent for publication}

Not applicable

\section{Competing interests}

The authors declare that they have no competing interests.

\section{Author details}

${ }^{1}$ Cell Biology Department, National Research Centre, Giza, Egypt.

${ }^{2}$ Department of Genetics, Faculty of Agriculture, Ain Shams University, Cairo, Egypt. ${ }^{3}$ Department of Animal Production, Faculty of Agriculture, Cairo University, Giza, Egypt.

Received: 17 December 2019 Accepted: 19 January 2020

Published online: 10 February 2020

\section{References}

1. Marwarha G, Ghribi O (2012) Leptin signaling and Alzheimer's disease. Am J Neurodegener Dis 1:245-265

2. Fernández-Formoso G, Pérez-Sieira S, González-Touceda D, Dieguez C, Tovar S (2015) Leptin, 20 years of searching for glucose homeostasis. Life Sci 140: 4-9

3. Vallinoto M, Schneider MP, Silva A, lannuzzi L, Brenig B (2004) Molecular cloning and analysis of the swamp and river buffalo leptin gene. Anim Genet 35:462-463

4. Liefers SC, Te Pas MF, Veerkamp RF, Chilliard Y, Delavaud C, Gerritsen R, Van Der Lende T (2003) Association of leptin gene polymorphisms with serum leptin concentration in dairy cows. Mamm Genome 14:657-663

5. Yazdani H, Rahmani HR, Edris MA, Dirandeh E (2010a) Association between A59V polymorphism in exon 3 of leptin gene and reproduction traits in cows of Iranian Holstein. Afr J Biotechnol 9:5997-6000

6. Clempson AM, Pollott GE, Brickell JS, Bourne NE, Munce N, Wathes DC (2011) Evidence that leptin genotype is associated with fertility, growth, and milk production in Holstein cows. J Dairy Sci 94:3618-3628

7. Komisarek J, Antkowiak I (2007) The relationship between leptin gene polymorphisms and reproductive traits in Jersey cows. Pol J Vet Sci 10:193-197

8. Orrú L, Terzano GM, Napolitano F, Savarese MC, De Matteis G, Scatä MC, Catillo G, Moioli B (2007) DNA polymorphisms in river buffalo leptin gene. Ital J Anim Sci 6(Suppl 2):342-344

9. Seong J, Kong HS (2012) Polymorphisms of LEP, LGB and PRLR in water buffalo. Korean J Agric Sci 39:577-581

10. Kale DS, Yadav BR, Mukherjee A, Prasad J (2013) Exploring DNA polymorphisms of leptin gene within Indian water buffaloes. J Adv Vet Res 3:20-26

11. Datta S, Verma A, Chatterjee P, Chatterjee AP (2013) Molecular characterization of the leptin gene in riverine buffaloes. Buffa Bul 32:196-211

12. Di Gregorio P, Di Trana A, Rando A, Celi P, Claps S (2014) Comparison of goat, sheep, cattle and water buffalo leptin (LEP) genes and effects of the Intron 1 microsatellite polymorphism in goats. Anim Prod Sci 54:1258-1262

13. Miller SA, Dykes DD, Polesky HF (1988) A simple salting out procedure for extracting DNA from human nucleated cells. Nucleic Acids Res 16:1215
14. Yazdani SK, Nakano M, Otsuka F, Kolodgie FD, Virmani R (2010b) Association between A59V polymorphism in exon 3 of leptin gene and reproduction traits in cows of Iranian Holstein. Eurolntervention 6:J24-J30

15. Di Finizio A, Guerriero G, Russo GL, Ciarcia G (2007) Identification of gadoid species (Pisces, Gadidae) by sequencing and PCR-RFLP analysis of mitochondrial 125 and 165 rRNA gene fragments. Eur Food Res Technol 225:337-344

16. Guerriero G, D'Errico G, Di Giaimo R, Rabbito D, Olanrewaju OS, Ciarcia G (2018) Reactive oxygen species and glutathione antioxidants in the testis of the soil biosentinel Podarcis sicula (Rafinesque 1810). Environ Sci Pollut Res Int 25:18286-18296

17. Dogan Rl, Getoor L, Wilbur WJ, Mount SM (2007) SplicePort--an interactive splice-site analysis tool. Nucleic Acids Res 35(Web Server issue):W285-W291

18. Chang TH, Huang HY, Hsu JB, Weng SL, Horng JT, Huang HD (2013) An enhanced computational platform for investigating the roles of regulatory RNA and for identifying functional RNA motifs. BMC Bioinformatics 14(Suppl 2):S4

19. Bendl J, Stourac J, Salanda O, Pavelka A, Wieben ED, Zendulka J, Brezovsky J, Damborsky J (2014) PredictSNP: robust and accurate consensus classifier for prediction of disease-related mutations. PLoS Comput Biol 10(1):e1003440

20. Yang J, Yan R, Roy A, Xu D, Poisson J, Zhang Y (2015) The I-TASSER Suite: protein structure and function prediction. Nat Methods 12(1):7-8

21. Savojardo C, Fariselli P, Martelli PL, Casadio R (2016) INPS-MD: a web server to predict stability of protein variants from sequence and structure. Bioinformatics. 32(16):2542-2544

22. Ashkenazy H, Abadi S, Martz E, Chay O, Mayrose I, Pupko T, Ben-Tal N (2016) ConSurf 2016: an improved methodology to estimate and visualize evolutionary conservation in macromolecules. Nucleic Acids Res 44(W1): W344-W350

23. Aboelenin MM, Mahrous KF, Elkerady A, Rashed MA (2017a) Molecular characterization of cytochrome P450 aromatase (CYP19) gene in Egyptian river buffaloes. Egypt J Genet Cytol 46:305-311

24. Aboelenin MM, Mahrous KF, Rashed MA, Sallam MA (2017b) Molecular characterization of tumor necrosis factor-a (TNFA) gene in Egyptian river buffaloes. Arab Univ J Agric Sci 25(2):367-375

25. Oberkofler H, Beer A, Breban D, Hell E, Krempler F, Patsch W (1997) Human obese gene expression: alternative splicing of mRNA and relation to adipose tissue localization. Obes Surg 7:390-396

26. Dye BT, Buvoli M, Mayer SA, Lin CH, Patton JG (1998) Enhancer elements activate the weak 3' splice site of alpha-tropomyosin exon 2. RNA. 4:1523-1536

27. Buratti E, Chivers M, Kralovicova J, Romano M, Baralle M, Krainer AR, Vorechovsky I (2007) Aberrant 5' splice sites in human disease genes: mutation pattern, nucleotide structure and comparison of computational tools that predict their utilization. Nucleic Acids Res 35:4250-4263

28. Haj Khelil A, Deguillien M, Moriniere M, Ben Chibani J, Baklouti F (2008) Cryptic splicing sites are differentially utilized in vivo. FEBS J 275:1150-1162

29. Buratti E, Chivers M, Hwang G, Vorechovsky I (2011) DBASS3 and DBASS5: databases of aberrant 3'- and 5'-splice sites. Nucleic Acids Res 39:D86-D91

30. Caminsky N, Mucaki EJ, Rogan PK (2014) Interpretation of mRNA splicing mutations in genetic disease: review of the literature and guidelines for information-theoretical analysis. F1000Res 3:282

31. Sibley CR, Blazquez L, Ule J (2016) Lessons from non-canonical splicing. Nat Rev Genet 17:407-421

32. Wang J, Smith PJ, Krainer AR, Zhang MQ (2005) Distribution of SR protein exonic splicing enhancer motifs in human protein-coding genes. Nucleic Acids Res 33:5053-5062

33. Braunschweig U, Barbosa-Morais NL, Pan Q, Nachman EN, Alipanahi B, Gonatopoulos-Pournatzis T, Frey B, Irimia M, Blencowe BJ (2014) Widespread intron retention in mammals functionally tunes transcriptomes. Genome Res 24:1774-1786

34. Martelli PL, Fariselli P, Savojardo C, Babbi G, Aggazio F, Casadio R (2016) Large scale analysis of protein stability in OMIM disease related human protein variants. BMC Genomics 17(Suppl. 2):397

35. Shabana SH, Hasnain S (2016) The p. N103K mutation of leptin (LEP) gene and severe early onset obesity in Pakistan. Biol Res 49:23

\section{Publisher's Note}

Springer Nature remains neutral with regard to jurisdictional claims in published maps and institutional affiliations. 